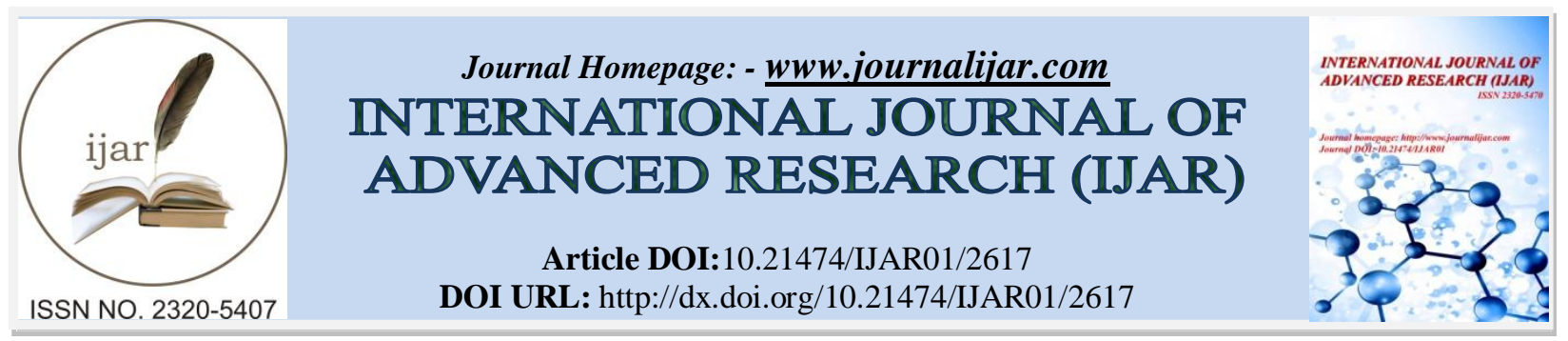

RESEARCH ARTICLE

\title{
MNDO STUDY OF THE MECHANISM OF THE ACID-CATALYZED REARRANGEMENT OF 3-ACETYL-6-ETHOXY-5,6-DIHYDRO-4H-1,2-OXAZINE.
}

Dr. Einas Ali Mohamed* and Dr. Ibrahim Mukhtar Ahmed.

Assistant Professor, Chemistry Department, Faculty of Education, Khartoum University, P.O. Box 406 Omdurman Sudan.

\section{Manuscript Info}

(.........................

Manuscript History

Received: 30 October 2016

Final Accepted: 29 November 2016

Published: December 2016

Key words:-

1,2-oxazines reduction; nitrones;

pyridine $\mathrm{N}$-oxides; reaction coordinates; semi-empirical calculations.

\section{Abstract}

MNDO semi-empirical calculations are reported for the gas-phase acid-catalyzed rearrangement of the 3-acetyl-6-ethoxy-5,6-dihydro$4 \mathrm{H}-1,2$-oxazine. Insight into the reaction mechanism may be obtained by the theoretical study of the reaction hyper surface and intrinsic reaction coordinate analysis by semi-empirical mechanical calculations.

The potential energy surface of the reaction is determined by characterizing intermediates and transition states, the reaction is found to take place by a step-wise mechanism involves protonation of the ring oxygen, subsequent $\mathrm{C}-\mathrm{O}$ bond cleavage reproduces the oxime, which cyclized to the five membered nitrone on which the solvent methanol affected the protonated alcohol exchange. $\mathrm{N}-\mathrm{C}$ bond cleavage (oxime exchange), followed by cyclization utilizing the carbonyl carbon produces the six membered ring, aromatization reproduces the desired pyridine $\mathrm{N}$-oxide cation.

The acid-catalyzed rearrangements of 1,2-oxazines was found to involve the ring $\mathrm{C}-\mathrm{O}$ bond cleavage.

Copy Right, IJAR, 2016,. All rights reserved.

\section{Introduction:-}

Oxazines have been explored as heterocyclic precursors, the original purpose of studying the acid-catalyzed rearrangements of 1,2-oxazines was to convert them to 1-hydroxy pyrroles. A good yield of the pyrrole was obtained by zinc-acetic acid reduction of some of the oxazines, the reaction was not applicable to most of the 1,2-oxazines studied and accordingly pyrrole formation was limited to a few cases, substituents remote to the reacting center affect the reaction course and limit its utility (Faragher and Gilchrist, 1979; Deady,1967). Theoretical study might help in justifying the lack of generality of these reactions and hence a cure could be found, it also may explain the difficulty in reduction of some of the oxazines.

The project is based in the study of the acid rearrangement of some of 5,6-dihydro- $4 \mathrm{H}-1,2$-oxazines, the pyridine $\mathrm{N}$ oxide was isolated from the acetyl oxazine when it was treated with methanol saturated with hydrogen chloride gas, the analogous oxazine with phenyl in place of the acetyl group cannot give a pyridine under the same acid conditions, instead the nitrone was obtained. The product from the reaction of the acetyl oxazine with glacial acetic acid saturated with hydrogen chloride gas was a different pyridine (Gilchrist et al., 1981, 1985).

Corresponding Author:-Dr. Einas Ali Mohamed.

Address:-Assistant Professor, Chemistry Department, Faculty of Education, Khartoum University, P.O.

Box 406 Omdurman - Sudan. 


\section{Results and Discussion:-}

All equilibrium geometries and transition states are stationary points on the energy hyper surfaces, all transition states were proven by vibrational analysis showing single negative vibration. The calculated heats of formation for relevant stationary points are listed in Table $\mathbf{1}$ and Table $\mathbf{2}$.

The general scheme of the proposed MNDO mechanism for the gas-phase acid-catalyzed rearrangement of the 3acetyl-6-ethoxy-5,6-dihydro-4H-1,2-oxazine is shown in Figure 1. The MNDO calculated structures (Ortep-3 plots) of the stationary points are shown in Figures $\mathbf{2}$ and 3. Figure $\mathbf{2}$ shows the structure of the oxazine, whereas the intermediates (denoted as A, B, C... T) and the transition states (denoted as TSAB..... ) are shown in Figure 3.

The discussion is based on the MNDO energies and optimized geometries, the combination of the acetyl oxazine with the proton, involves in the first step protonation at the carbonyl oxygen $\mathrm{O}(11)$ (indicating greater basicity) as a more stable intermediate oxonium ion A. Consequently, a considerable change in the oxygen atom charge, along with an increase in the carbonyl distance (indicating partial single bond character) were observed. Also the formal charges of the other hetero atoms are changed in comparison to the corresponding values in the parent oxazine, indicating electrostatic interaction with the incoming proton.

It is interesting to note that the energy is raised as the proton combine with the oxazine, in accordance with the results reported in similar theoretical studies of acid-catalyzed rearrangement of 1,4-dione compounds derived from steroids (Lorenc et al., 1999). Also this could be due to the fact that MNDO is parameterized to reproduce groundstate properties of neutral closed-shell molecules (Dewar and Healy, 1984).

Transformations involve $\mathrm{H}$ migration are detected in many steps throughout the reaction path investigated, they proceed with high activation. The energy rich five (TSAB and TSPQ), four (TSHI, TSIJ,TSMN and TSRS)and three (TSBC and TSQR) membered ring transition states observed throughout $\mathrm{H}$ migration, could be explained in terms of the known propensity of hydrogen to form the strong 2- electron 3- center bonds. The energy of the transition state is high not only because of the strain in the three or four membered rings, but also of interatomic repulsion between the two oppositely charged atoms which are forced to approach each other at closer distance in the transition state. Also the high energy calculated, could well be due to the known propensity of MNDO method to overestimate the activation energy of $\mathrm{H}$ migration reactions (Kakkar et al., 2001; Dewar, 1984). The charges of the atoms from and to which the proton migrates and the charge of the hydrogen itself are changed as a consequence of these transformations.

Ring opening were encountered in $\mathbf{C} \rightarrow \mathbf{D}$ and $\mathbf{K} \rightarrow \mathbf{L}$ transformations, the former involves $\mathrm{C}(6)-\mathrm{O}(1)$ bond cleavage in $\mathbf{C}$ to produces the more stable open chain oxime $\mathbf{D}$, where in the later $\mathbf{K}$ underwent ring opening through $\mathrm{C}(2)-\mathrm{N}(1)$ bond cleavage to the less stable oxime $\mathbf{L}$, in order for the reaction to take place a $\mathrm{C}-\mathrm{O}$ (ether bond) double bond is formed along with a decrease of the ether $\mathrm{O}$ negative charge. The reaction proceeds with low activation through the transition state TSCD and TSKL, the structure of the transition state is of reactant-like feature, indicated by the breaking bond length which is close to the value in the reactant, and a decrease in $\mathrm{C}-\mathrm{O}$ distance (indicating partial double bond character), since ring opening is exothermic, the case accords to Hammond postulate (Hammond, 1955).

Due to the large separation between the reacting centers, $\mathrm{N}(2) \ldots . \mathrm{C}(6)$ in $\mathbf{D}$ and of $\mathrm{N}(1) \ldots . . \mathrm{C}(11)$ in $\mathbf{N}$, intramolecular cyclization to form the nitrone $\mathbf{F}$ and the six membered cyclic intermediate $\mathbf{P}$, is produced by rotation about $\mathbf{C}(5)-$ $\mathrm{C}(4)$ and $\mathrm{C}(13)-\mathrm{C}(11)$ single bonds to form the higher energy conformers Eand $\mathbf{O}$ respectively (with the minimum interatomic distance) (Konuklar, 2001). As a result of the induced rotation, no change observed in bond lengths in going from theparent intermediate to its conformer except the shortening of the distance between the reacting centers and a slight change in some charges. There is no transition state corresponding to this conformational change exist, at least according to the MNDO method.

Intramolecular cyclization is observed in transformations of the oxime $\mathbf{E}$ to produce the more stable quasi planar five membered nitrone cation $\mathbf{F}$, and of the oxime $\mathbf{O}$ to formthe six membered cyclic intermediate $\mathbf{P}$, the energy dropped as a consequence of cyclization. The reaction proceeds with low activation, indicated by the forming $\mathrm{C}-\mathrm{N}$ bond and consequent increase in $\mathrm{C}-\mathrm{O}$ bond, the transition state TSEF is of reactant-like feature, in contrast to Hammond postulate, whereas the transition state TSOP accords with Hammond postulate as being of product-like feature. 
In order for the solvent methanol to affect the protonated alcohol (ethanol) exchange it approaches the nitrone $\mathbf{F}$ at the top of the ring forming $\mathbf{G}$, as a result the energy dropped with no change in the geometry of the nitrone $\mathbf{F}$ (labeling of the atoms in intermediate $\mathbf{G}$ is changed according to its formation).

The ethanol molecule departs in consecutive steps from $\mathbf{G}$ to $\mathbf{K}$ involving proton migration from $\mathrm{O}(17)$ to $\mathrm{N}(1)$ in $\mathbf{I}$ and then to $\mathrm{O}(6)$ in $\mathbf{J}$,asa result the nitrone $\mathbf{K}$ is formed. It is interesting to note thatthe breaking of carbon-oxygen bond proceeds with low activation and proton transfer is associated with this process, in opposed to its formation which proceeds with high activation $(\mathbf{G} \rightarrow \mathbf{H})$.

$\mathrm{H}(24)$ in $\mathbf{L}$ is attached to $\mathrm{C}(2)$ producing the high energy carbocation $\mathbf{M}$, the high energy planar three membered ring of $\mathrm{C}(3) \mathrm{C}(2) \mathrm{H}(24)$ transition state TSLMdescribing this transformation, the decrease of $\mathrm{C}(2)-\mathrm{C}(3)$ distance and of $\mathrm{C}(2)$ positive charge and the increase of $\mathrm{C}(3)$ positive charge indicate increasing carbocation character. The high energy observed could be explained according to the fact that, hydrogen migration to a carbon atom involves unfavorable change in its hybridization and a corresponding contribution to activation of the reaction in question (Dewar, 1984).

The carbocation $\mathbf{M}$ is transformed to a more stable oxonium intermediate $\mathbf{N}$, where $\mathrm{H}(24)$ is attached to the carbonyl oxygen $\mathrm{O}(12)$, in order to facilitate the intramolecular nucleophilic attack of $\mathrm{N}(1)$ at the carbonyl carbon $\mathrm{C}(11)$, basing on the fact that protonation at the carbonyl oxygen will enhance the electrophilicity of the carbonyl carbon atom towards the nucleophilic attack (Jones, 1979), which in turn produces the six membered pyridine oxide ring, according to the fact that, pyridine oxides are obtained through intermolecular cyclization of oximes (Katritzky and Lagowski, 1971).

$\mathbf{Q}$ is transferredto the more stable oxonium ion $\mathbf{R}$, where $\mathrm{H}(8)(\mathrm{H}(26)$ in $\mathbf{Q})$ is attached in the first step to $\mathrm{C}(6)(\mathrm{C}(5)$ in $\mathbf{Q})$. $\mathbf{R}$ is characterized by the $\mathrm{N}(1)-\mathrm{C}(2)(\mathrm{N}(1)-\mathrm{C}(11)$ in $\mathbf{Q})$ bond cleavage in an unusual manner, and transformed to the more stable oxonium ion $\mathbf{S}$, where $\mathrm{H}(8)$ is attached to $\mathrm{O}(20)$ accompanied by a considerable increase in its positive charge (the more positive $\mathrm{H}$ which will be abstracted in basic medium). Both transformations take place through the high energy transition states TSQR and TSRS, which are characterized by a considerable change of some bonds distances indicating partial single and double bond characters and of atoms charges compared to the same values in the reactants. In addition, the planar three membered and four membered ring, which normally observed in $\mathrm{H}$ migration reactions are detected.

It is interesting to note that tautomerism exists between $\mathbf{Q}$ (the $\mathbf{N}$-oxide form) and $\mathbf{S}$ (the hydroxyl amine form), and that the hydroxyl amine form predominates by $34.69 \mathrm{Kcal} / \mathrm{mole}$.

Theoxonium ion $\mathbf{S}$ is transformed to the most stable pyridine $\mathrm{N}$-oxide cation $\mathbf{T}$, where water molecule departs, accordingly the ring becomes aromatic characterized by the planar conformation and the bond lengths ranging from $1.40 \AA$ to $1.44 \AA$ for all atom pairs in the ring. The low energy transition state TSST describing this transformation is of reactant-like feature.

It is interesting to note that aromatization proceed with very little activation, aromatization is necessarily a stabilizing process, it is therefore accompanied by a decrease in free energy, however this represents a balance between enthalpy and entropy effect (Jones, 1979). 


\section{Legend 1:-}

This legend shows the proposed mechanism of the reaction (Fig 1) as well as the optimized geometries of the stationary points (the 3-acetyl-6-ethoxy-5,6-dihydro-4H-1,2-oxazine (Fig 2), the intermediates and the transition states (Fig 3) calculated at the semi-empirical MNDO level of theory.

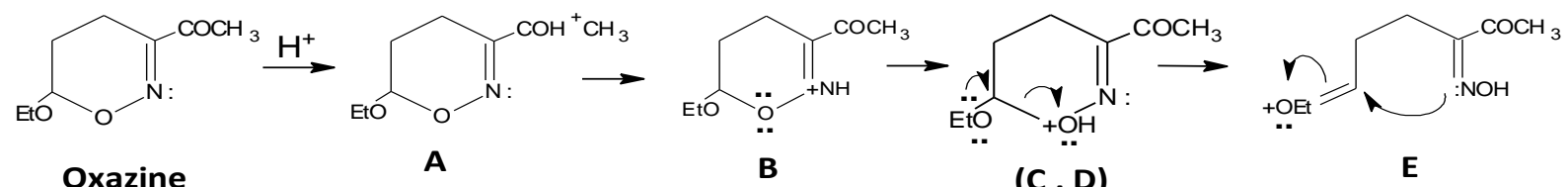

Oxazine

A

B<smiles></smiles><smiles>[Te]OC(I)I</smiles><smiles>COC(=O)C1(C(=O)O)CCC=[N+]1O</smiles>

K<smiles>COc1ccc[n+](O)c1CCCO</smiles>

L

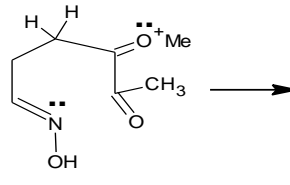<smiles>COC1(O)CCO[N+]1([O-])O</smiles>

I
(C , D)<smiles>CCOC1(OC)CCC(O)N1O</smiles>

H $\downarrow$

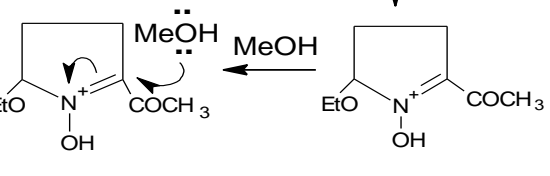

G

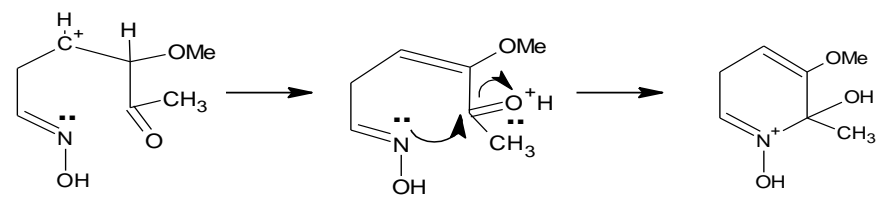

$(\mathrm{N}, \mathrm{O})$

M

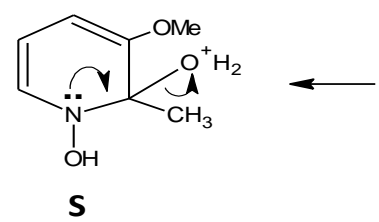<smiles>COc1ccc([18OH])c(C)c1O</smiles>

$\mathbf{R}$

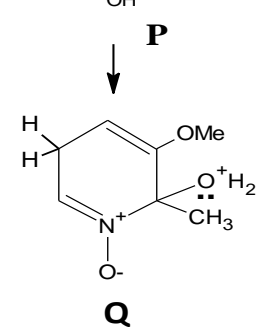

Figure 1:- The general scheme of the proposed MNDO mechanism of the acid-catalyzed rearrangement of 3-acetyl6-ethoxy-5,6-dihydro-4H-1,2-oxazine.

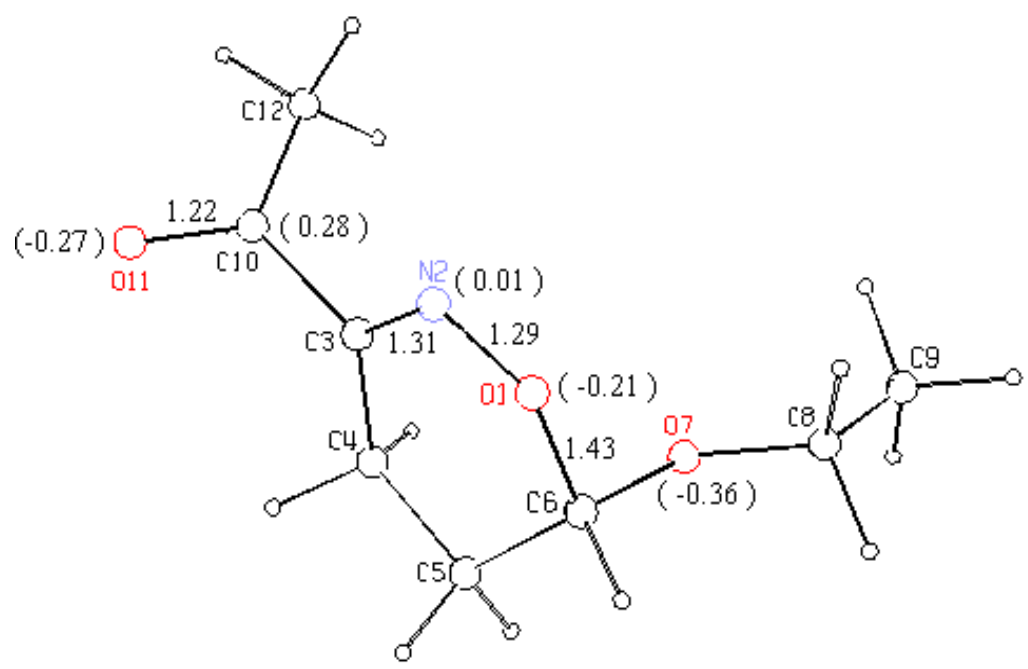

Figure 2:-The MNDO optimized geometry of the 3-acetyl-6-ethoxy-5,6-dihydro-4H-1,2-oxazine, the essential bond length in $\AA$ and charge distributions in atomic units of charge (e). 


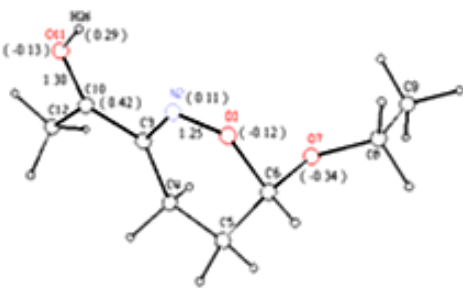

$A$

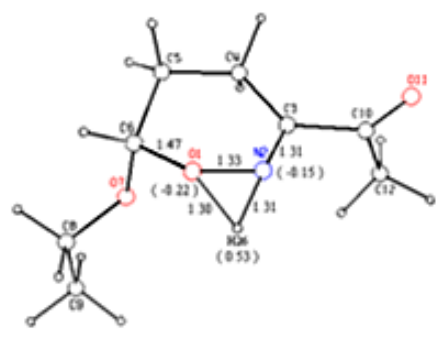

TSBC

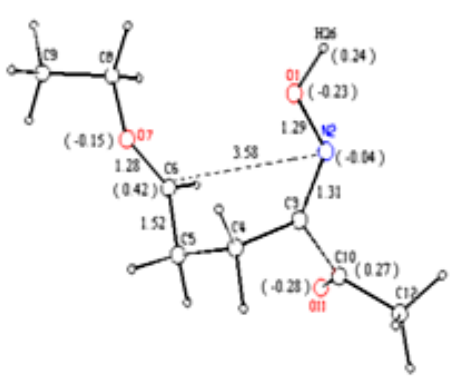

D

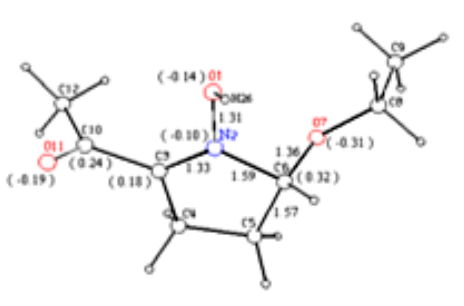

$\mathbf{F}$

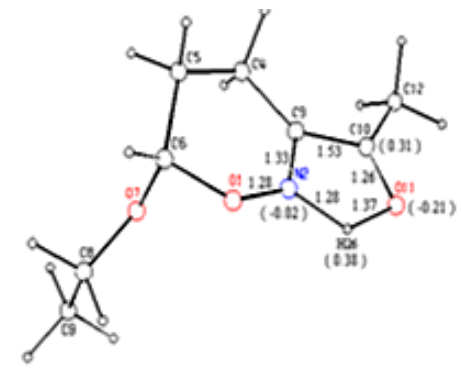

TS.AB

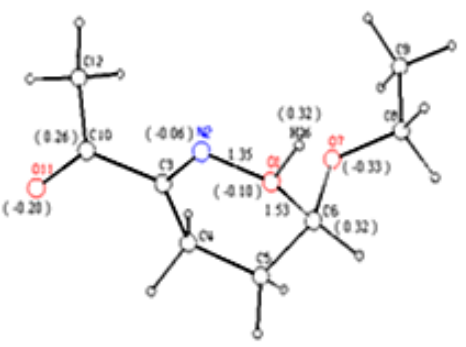

c

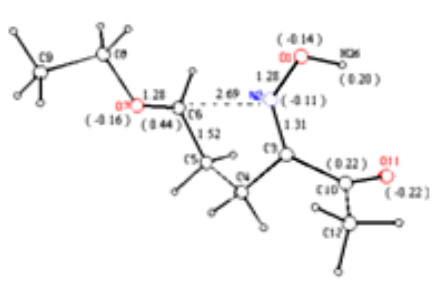

$\mathbf{E}$

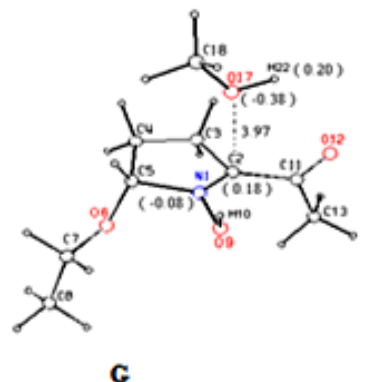

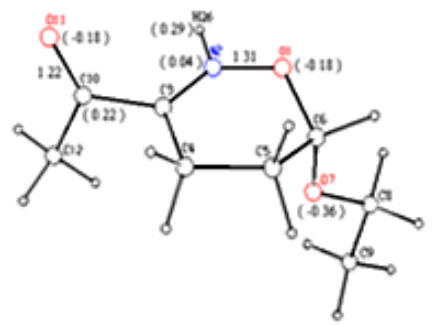

B

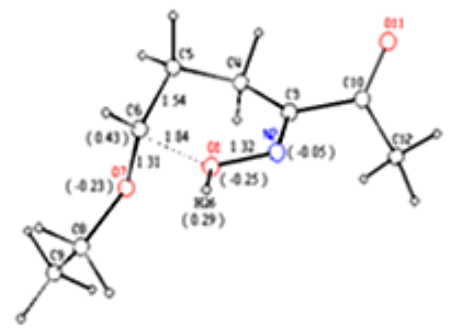

TSCD

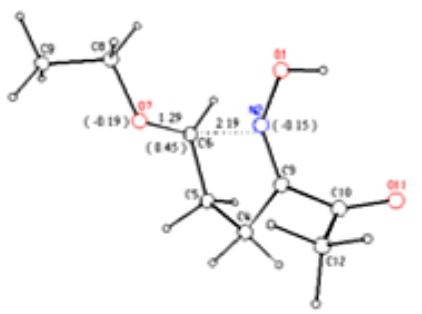

TSEF

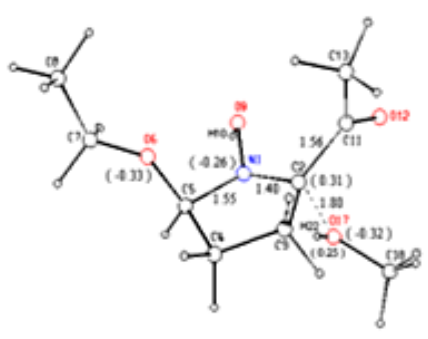

TSGH 


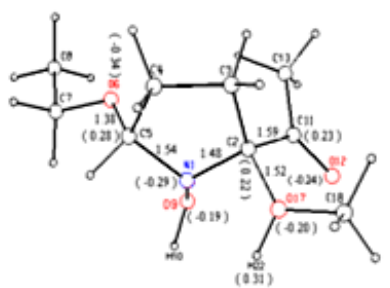

H

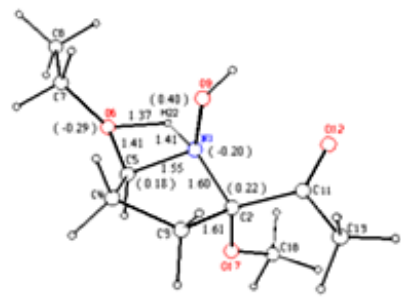

TSIJ

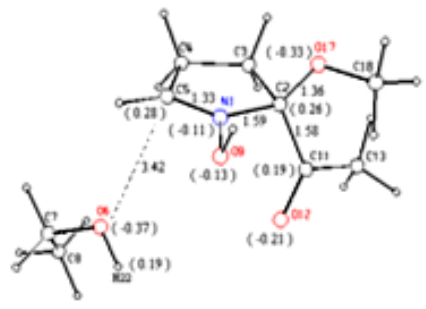

$\mathbf{K}$

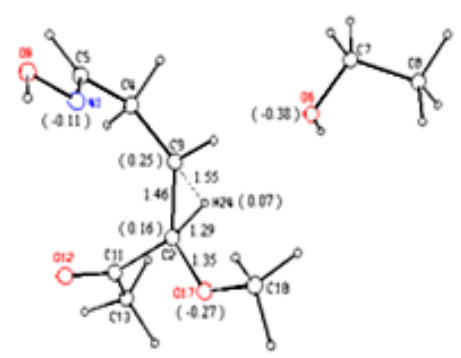

TSLM

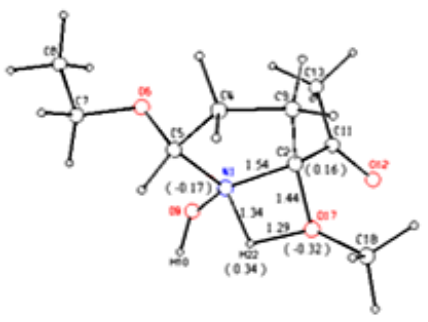

TSHI

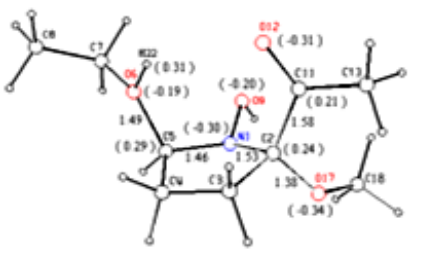

J

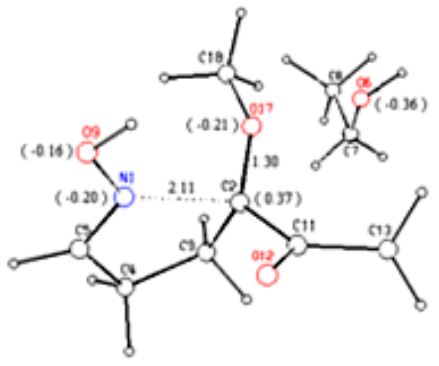

TSKI

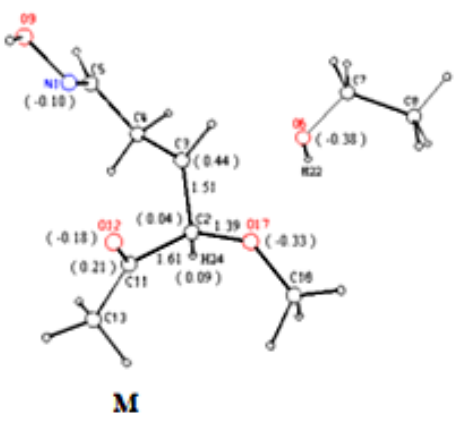

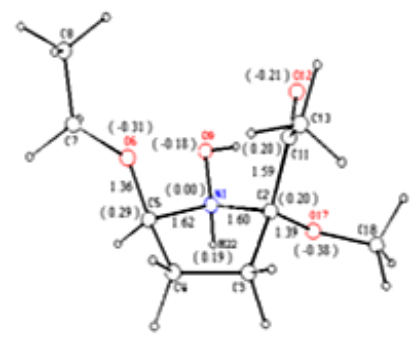

I

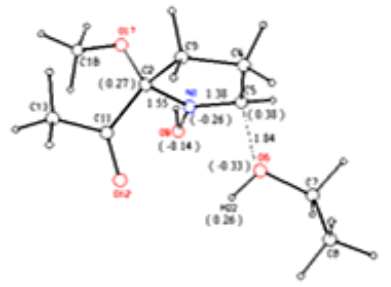

TSJK

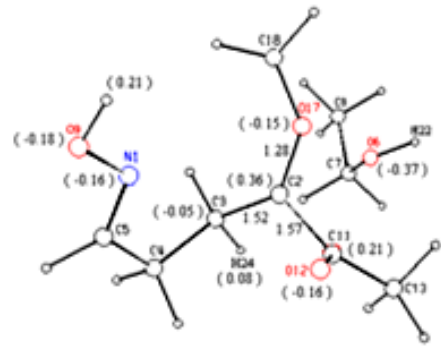

L

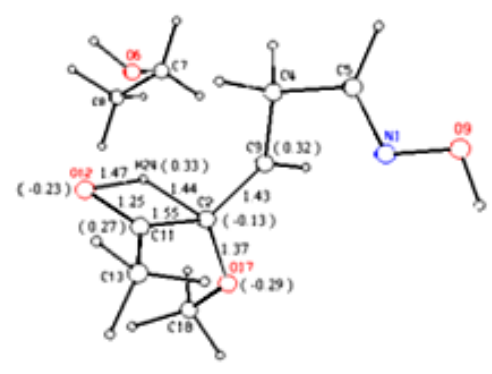

TSMN 


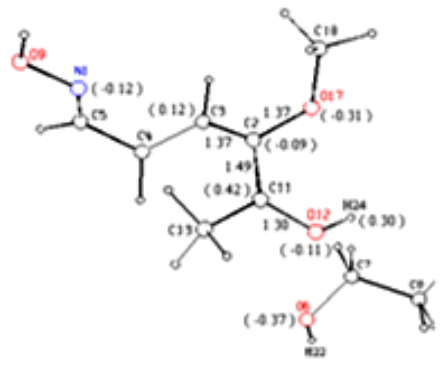

$\mathbf{N}$
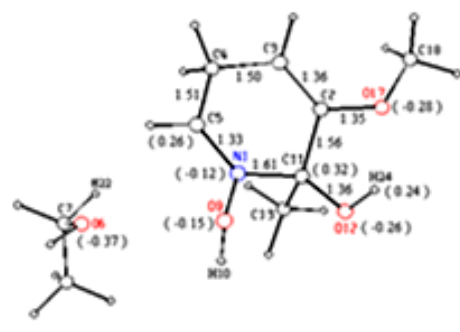

$\mathbf{P}$

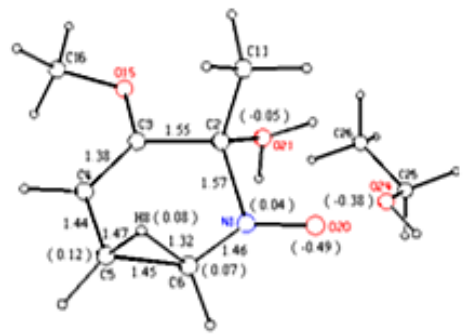

TSQR

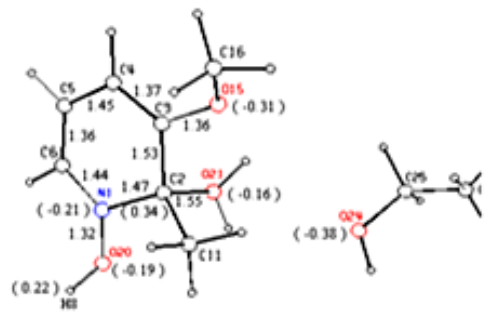

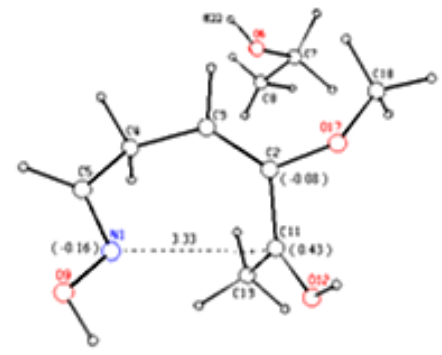

o

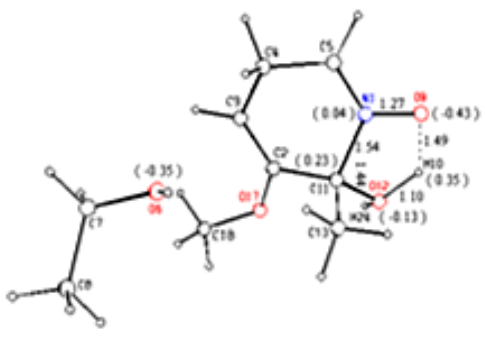

TSPQ

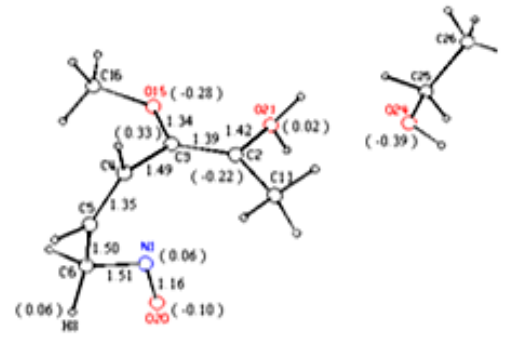

$\mathbf{R}$

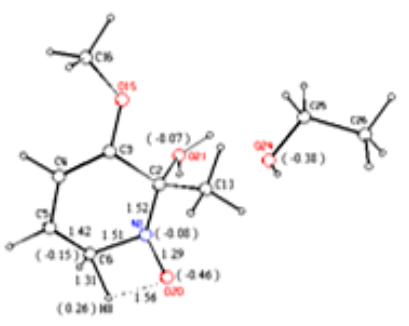

TSRS
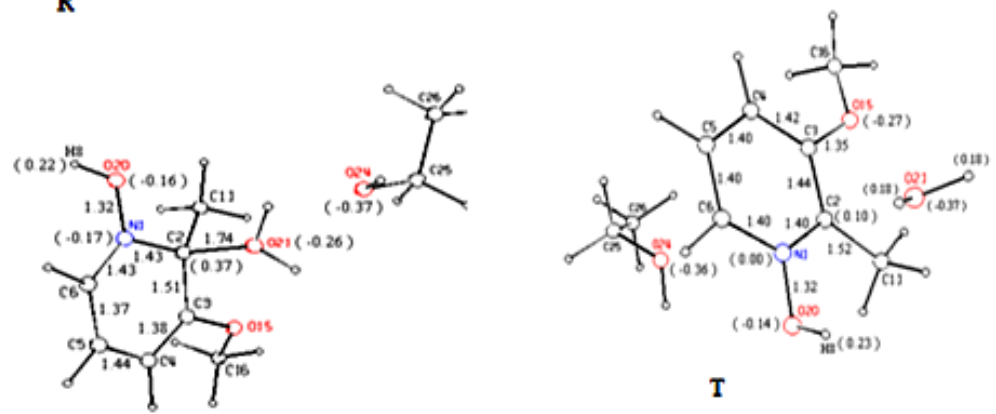

T

TSST

Figure 3:- The MNDO optimized geometries of the intermediates (A...T) and the transition states (TSAB...TSST), the essential bond length in $\AA$ and charge distributions in atomic units of charge (e).

\section{Legend 2:-}

This legend shows the heats $\mathrm{f}$ formations of the optimized geometries of the stationary points, the 3-acetyl-6-ethoxy5,6-dihydro-4H-1,2-oxazine and the intermediates (Table 1) and the transition states (Table 2), calculated at the semi-empirical MNDO level of theory. 
Table 1:- Heats of formation of the calculated stationary points (the 3-acetyl-6-ethoxy-5,6-dihydro-4H-1,2-oxazine and the intermediates A-T).

\begin{tabular}{|c|c|}
\hline Stationary Point & Heat of formation, Kcal/mole \\
\hline Oxazine & -96.22 \\
\hline A & 73.03 \\
\hline B & 87.39 \\
\hline C & 97.20 \\
\hline D & 85.66 \\
\hline F & 89.28 \\
\hline G & 79.24 \\
\hline H & 16.62 \\
\hline I & 45.65 \\
\hline J & 46.09 \\
\hline K & 45.01 \\
\hline $\mathbf{L}$ & 29.43 \\
\hline $\mathbf{M}$ & 30.26 \\
\hline $\mathbf{N}$ & 61.84 \\
\hline $\mathbf{O}$ & 26.44 \\
\hline $\mathbf{P}$ & 27.06 \\
\hline $\mathbf{Q}$ & 26.88 \\
\hline $\mathbf{R}$ & 76.86 \\
\hline S & 46.53 \\
\hline T & 42.17 \\
\hline & 9.83 \\
\hline
\end{tabular}

Table 2:-Heats of formation of the calculated stationary points (the transition states TSAB -TSST).

\begin{tabular}{|c|c|}
\hline Stationary Point & Heat of formation, Kcal/mole \\
\hline TSAB & 121.01 \\
\hline TSBC & 153.06 \\
\hline TSCD & 101.49 \\
\hline TSEF & 90.42 \\
\hline TSGH & 49.98 \\
\hline TSHI & 81.25 \\
\hline TSIJ & 119.05 \\
\hline TSJK & 50.71 \\
\hline TSKL & 36.88 \\
\hline TSLM & 77.49 \\
\hline TSMN & 109.98 \\
\hline TSOP & 35.29 \\
\hline TSPQ & 86.37 \\
\hline TSQR & 135.72 \\
\hline TSRS & 149.62 \\
\hline TSST & 43.18 \\
\hline
\end{tabular}

\section{Conclusion:-}

Although semi-empirical methods such as MNDO will undoubtedly provide useful information concerning some of the details of chemical transformations, it is important that extensive $a b$ initio calculations and experimental kinetic studies be performed on such reactions, in order that the reliability of the semi-empirical methods can be properly evaluated.

\section{Methods:-}

The geometries and charge distributions of stationary points were determined by the standard semi-empirical molecular orbital method MNDO as implemented in MOPAC package version 6, employing full geometry 
optimization with no assumption made regarding symmetry (Dewar and Thiel, 1977a,b; Dewar and Wade, 1977; Young, 2001; Stewart, 1990).

The calculation of equilibrium geometries involves the minimization of the potential energy function with respect to the degrees of freedom of the molecule. The molecular geometries were optimized using the eigenvector following routine (EF), the Saddle and reaction path calculations methods were used to get first approximations of the transition states, which were then further refined using EF procedure.

Further characterization of the stationary points as equilibrium geometries or transition states was performed by force calculations. All the equilibrium geometries have all positive force constants (positive frequencies) and the transition states have one and only one negative force constant (imaginary frequency), belonging to the critical bonds. In order to ensure sufficient accuracy in the calculations, the six vibrational frequencies corresponding to rotation and translation, while never zero were usually less than about $10 \mathrm{~cm}^{-1}$. Intrinsic reaction coordinate calculations (IRC) were performed to verify correspondence of the calculated transition states to the reactants and products (Baker, 1986).

The software utilized in the study:MOPAC 6.0 for Windows 95, MOLDA for protein modeling (Yoshida, 2003), ACD/ChemSketch-version 11 and Ortep-3 for Windows-version 2 (Farrugia, 1997).

\section{Acknowledgements:-}

We would like to thank Khartoum Universityfor financial support for this researchin the PhD stage.

\section{References:-}

1. Baker, J. (1986), J. Comput. Chem., 7(4): 385-395.

2. Deady, L.W. (1967), Tetrahedron,(23): 3505-3509.

3. Dewar, M.J.S. (1984), J. Am. Chem. Soc., 106(1): 209-219.

4. Dewar, M.J.S. and Wade, L.E. Jr. (1977), J. Am. Chem. Soc., 99(13): 4417-4424.

5. Dewar, M.J.S. and Thiel, W. (1977a), J. Am. Chem. Soc., 99(15): $4899-4907$.

6. Dewar, M.J.S. and Thiel, W. (1977b), J. Am. Chem. Soc., 99(15): 4907- 4917.

7. Faragher, R. and Gilchrist, T.L. (1979), J. Chem. Soc. Perkin Trans.1,258-262.

8. Farrugia, L. J. (1997), J. Appl. Cryst.,(30): 565.

9. Gilchrist, T.L., Iskander, G.M. and Yagoub, A.K. (1981),J. Chem. Soc. Chem. Commun., 696 - 698.

10. Gilchrist, T.L., Iskander, G.M. and Yagoub, A.K. (1985), J. Chem. Soc. Perkin Trans. 1,2769-2773.

11. Hammond, G.S. (1955), J. Am. Chem. Soc., (77): 334-338.

12. Jones, R.A.Y. (1979): Physical and Mechanistic Organic Chemistry; Cambridge University press.

13. Kakkar, R., Sarma, B. K. and Katoch, V. (2001), Proc. Indian Acad. Sci. (Chem. Sci.), 113( 4): $297-306$.

14. Katritzky, A.R. and Lagowski, J.M. (1971): Chemistry of the Heterocyclic N-Oxides; Academic press, Inc. Ltd: London, pp 74-75.

15. Konuklar, F.A., Aviyente, V., Sen, T. Z. and Bahar, I. (2001), J. Mol. Model, (7): 147-160.

16. Lorenc, L., Pavlovich, V.; Juranich, I., Mihailovich, M.Lj., Bondarenko-Gheorghiu, L., Krstich, N. and Dabovich, M. (1999), Molecules, (4): 272-278.

17. Stewart, J.J.P. (1990): MOPAC Manual, sixth edition, Seiler, F. J. Research Laboratory, United States Air Force Academy, CO 80840.

18. Yoshida, H.(2003),J. Comput. Chem. Jpn., (2):143-148.

19. Young, D.C. (2001): Computational Chemistry: A practical Guide for Applying Techniques to Real World Problems; John Wiley \& Sons, Inc.,Semiempirical Methods, pp 32-41.Computer software:-

1. MOPAC 6.0 for Windows 95. Retrieved from:

2. http://www.ccl.net/cca/software/MS-WIN95-NT/mopac6/index.shtml

3. MOLDA for protein modeling. Retrieved from:

4. http://www.molda.org/

5. ACD/ChemSketch Version 11. Retrieved from:

6. http://www.acdlabs.com/

7. ORTEP-3 for Windows. Retrieved from:

8. http://www.chem.gla.ac.uk/ louis/software/ortep3/ 